\title{
Production of GAWK (Chromogranin-B 420-493)-like Immunoreactivity by Endocrine Tumors and Its Possible Diagnostic Value
}

\author{
K. Sekiya, M. A. Ghatei, M. J. Salahuddin, A. E. Bishop,“ Q. A. Hamid, * H. Ibayashi,` J. M. Polak, * and S. R. Bloom \\ Departments of Medicine and *Histochemistry, Royal Postgraduate Medical School, Hammersmith Hospital, London W12 ONN, \\ United Kingdom; and ${ }^{\ddagger}$ Third Department of Internal Medicine, Faculty of Medicine, Kyushu University, Fukuoka 812, Japan
}

\begin{abstract}
GA WK (chromogranin-B 420-493) is a 74 amino acid peptide recently isolated from human pituitaries. Using two different antibodies (directed against GAWK [1-17] and [20-38] fragments) GAWK-LI was measured in tumors from 194 patients and in the plasma of 434 patients by RIA.

The highest tissue concentrations of GAWK-LI were found in pheochromocytoma (GAWK [1-17]-LI, 18,173 $\pm 3,915$; GAWK [20-38]-LI, 17,852 $\pm 2,763$ [mean + SEM] pmol/g wet wt tissue; $n=9$ ), which were at least ten times higher than any other tumors producing GAWK-LI. High concentrations of GAWK-LI were also found in other types of endocrine tumors including carcinoid, medullary carcinoma of thyroid, pancreatic, and ACTH-producing lung tumors. On the other hand, low concentrations of GAWK-LI were found in nonendocrine tumors.

Plasma concentrations of GAWK-LI were found to be elevated in patients with endocrine tumor, but more so in those with pancreatic tumors than with pheochromocytomas. Plasma concentrations returned to normal after successful tumor removal. Chromatographic profiles of GAWK-LI in extracts of pheochromocytomas and normal adrenals showed high molecular weight peaks that were absent in the extracts of other endocrine tumors and normal pancreas, suggesting differential tissue-specific processing. Thus GAWK-LI is produced by a variety of endocrine tumors and may serve as a plasma tumor marker, especially in patients with pancreatic endocrine tumors.
\end{abstract}

\section{Introduction}

A partial sequence of chromogranin-B (420-493) has been isolated from the human pituitary and designated GAWK (1-3; Fig. 1). The family of proteins called chromogranins, originally found in chromaffin cells (4), are now thought to be universal markers for neuroendocrine tissues and tumors (5-13). Recently the amino acid sequences of human chromogranin $A(C g A)$ and $B(C g B)$ have been reported and shown to be very different from each other, particularly in the central section $(3,14)$. Thus, there is no GAWK sequence anywhere within the $\mathrm{CgA}$ molecule. One of the proposed functions of the

Address correspondence to Dr. S. R. Bloom, Department of Medicine, Royal Postgraduate Medical School, Du Cane Road, London W12 ONN, UK.

Received for publication 18 April 1988 and in revised form 16 December 1988.

J. Clin. Invest.

(c) The American Society for Clinical Investigation, Inc.

$0021-9738 / 89 / 06 / 1834 / 09 \$ 2.00$

Volume 83, June 1989, 1834-1842 chromogranins is that they are precursors of peptide hormones. For example, the sequence of pancreastatin, a peptide that may be involved in the regulation of insulin secretion, is contained within $\mathrm{CgA}(14,15)$. The GAWK sequence is contained within $\mathrm{CgB}$ but as yet has not been shown to have a physiological role. Histochemical and RIA studies have shown the concentration of $\mathrm{CgA}$ to be elevated in endocrine tumors (6-10, 16-19). However, the concentrations of $\mathrm{CgB}$ or the $\mathrm{CgB}$ fragment peptide (GAWK) in endocrine tumors and plasma have not previously been reported. We developed two RIA systems using antibodies to GAWK (1-17) and GAWK (20-38) to measure GAWK-like immunoreactivities (GAWK [1-17]-LI and GAWK [20-38]-LI) in different types of endocrine tumors and in plasma obtained from patients with those tumors before and after removal by surgery. GAWK-LI was characterized by chromatography and the concentration of GAWK-LI was measured in plasma from the adrenal and peripheral veins to investigate the possible source of circulating GAWK-LI. In addition, localization of GAWK-LI in tissue sections of endocrine tumors was carried out by immunocytochemistry.

\section{Methods}

Tissues. Endocrine tumor tissues $(n=194)$ were obtained at surgical resection. Immediately after removal the tissues were snap-frozen in liquid nitrogen and stored at $-70^{\circ} \mathrm{C}$ or below for subsequent peptide extraction or fixed by immersion in Bouin's solution for histological examination. Specimens of normal human pancreas $(n=8$; one obtained at operation, seven at postmortem; median, $13.3 \mathrm{~h}$; range, 5.5-28 $\mathrm{h}$ after death) and adrenal gland $(n=15$; nine operative, six postmortem; median, $12.0 \mathrm{~h}$; range, 6-24 h after death) were obtained. These tissues, thought clinically not to be involved in any pathological process, were subjected to microscopic examination and only included if shown to be histologically normal.

Tissue extraction. Tissues for RIA were extracted in $0.5 \mathrm{M}$ acetic acid $\left(10 \mathrm{ml} / \mathrm{g}\right.$ wet wt tissue) for $15 \mathrm{~min}$ at $100^{\circ} \mathrm{C}$. The acetic acid method was chosen after a preliminary study of five different extraction procedures $(0.5 \mathrm{M}$ acetic acid, $\mathrm{pH} 2.17 ; 0.1 \mathrm{M}$ acetic acid, $\mathrm{pH}$ 2.43; $0.1 \mathrm{M} \mathrm{HCl}$, pH 0.7; water, $\mathrm{pH} 7$; and $75 \%$ ethanol in $0.1 \mathrm{M} \mathrm{HCl}$ ) on several human tissue specimens. Water extraction resulted in only $32.6 \pm 8.5 \%$ recovery of GAWK (1-17) but $90.9 \pm 3.7 \%$ for GAWK (20-38) immunoreactivity (compared with acid extraction of human pituitaries, $n=30$ ). The other four extraction procedures showed almost identical recoveries, and $0.5 \mathrm{M}$ acetic acid was selected as it was the most commonly used in the peptide literature. We also examined three different boiling times $(10,30$, and $60 \mathrm{~min})$ with the above extraction procedures, with the exception of the $75 \%$ ethanol in $0.1 \mathrm{M}$ $\mathrm{HCl}$ method. There was no significant difference in the recoveries of GAWK-LI. A total of 194 tumor extracts were assayed.

Plasma samples. All samples were taken between 8:00 and 9:00 a.m. Plasma samples were obtained from 434 patients with various tumors, collected through the National Health Service Supraregional Assay Service (United Kingdom) and the Hospital of Kyushu University (Fukuoka, Japan) over the last $4 \mathrm{yr}$, including plasma samples 
Human Chromogranin-B

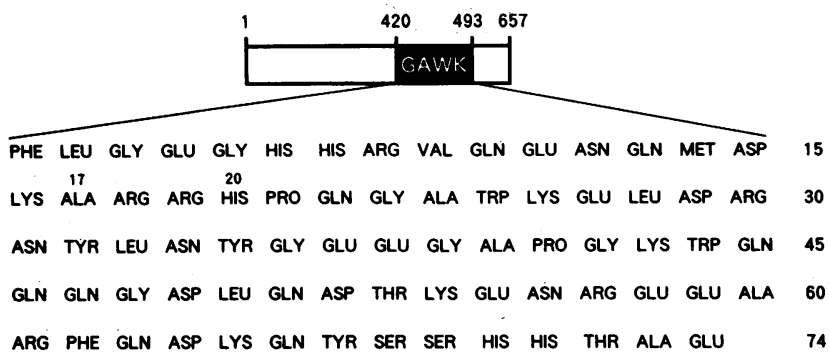

Figure 1. Amino acid sequence of GAWK. The sequence is identical to chromogranin-B 420-493 and is composed of 74 amino acids, having a mol wt of 8,795 .

from patients with suspected but subsequently unproven vasoactive intestinal peptide-producing tumors (VIPomas) ${ }^{1}$ and 40 normal subjects ( 9 women and 31 men, mean age $30 \mathrm{yr}$ ). Tumor patients were definitively diagnosed in each case by a combination of clinical and radiological features, specific hormone assays where applicable, and tissue biopsy when available. Postoperative plasma samples were obtained from five patients (four VIPomas and one pheochromocytoma) a few days after the successful removal of the tumor. Plasma samples of adrenal vein were obtained from patients $(n=12)$ receiving adrenal venography, and at the same time peripheral plasma samples were collected. All blood samples were collected into heparinized tubes containing 400 kallikrein inhibitory (KI) units aprotinin (Trasylol, Bayer, UK)/ml blood and immediately centrifuged, and the plasma was stored at $-20^{\circ} \mathrm{C}$ until assay. To assess the stability of GAWK-LI in plasma, seven plasma samples from patients with different endocrine tumors were left at room temperature with $10 \mathrm{U} / \mathrm{ml}$ lithium heparin and $400 \mathrm{KJ}$ units aprotinin for a total of $144 \mathrm{~h}$.

$R I A$. Fragments of peptide corresponding to residues 1-17 and 20-38 of GAWK were custom-synthesized by Cambridge Research Biochemical (Cambridge, UK) and Institut Armand-Frappier Biochemicals (LaVal, Quebec, Canada), respectively, and conjugated to BSA with glutaraldehyde (20). 16 half lop-eared rabbits were immunized with the conjugate emulsified in complete Freund's adjuvant for the primary immunization and incomplete adjuvant for booster injection. Two rabbits, one named YE-4 for GAWK (1-17) and the other named YS-1 for GAWK (20-38), produced antisera of sufficiently high affinity to be useful for both RIAs of plasma samples, tissue extracts, and immunocytochemistry. The optimal dilutions for RIA were found to be 1:16,000 for YE-4 and 1:24,000 for YS-1. The antisera were characterized by assessing their ability to bind labeled synthetic GAWK fragments. No crossreaction was seen with other peptides tested (growth hormone [GH], prolactin [PRL], thyroid stimulating hormone, luteinizing hormone, follicle stimulating hormone, ACTH, beta lipotropin, beta endorphin, thyrotropin releasing hormone, luteinizing hormone-releasing hormone, corticotrophin-releasing hormone, GH-releasing hormone [GRH], lysine-vasopressin, insulin, glucagon, somatostatin [SRIF], and vasoactive intestinal polypeptide [VIP]). Synthetic GAWK fragments (1-17 or 20-38) and ${ }^{125}$ I-GAWK fragments were used as standards and tracers. Iodination of the GAWK fragments was performed by the chloramine-T method (21). Purification of the iodinated product was performed by reverse phase HPLC using a $5-\mu \mathrm{m}$ Techsil C-18 column $(3.9 \times 300 \mathrm{~mm})$ and eluted with $17.5 \%(\mathrm{vol} / \mathrm{vol})$ acetonitrile $(\mathrm{ACN})$ in $0.1 \%(\mathrm{vol} / \mathrm{vol})$

1. Abbreviations used in this paper: ACN, acetonitrile; FPLC, fast protein liquid chromatography; GH, growth hormone; GRH, GH-releasing hormone; Kav, elution coefficient; MEA, multiple endocrine adenomatosis; PRL, prolactin; SRIF, somatostatin; TFA, trifluoracetic acid; VIP, vasoactive intestinal polypeptide; VIPomas, vasoactive intestinal peptide-producing tumors. aqueous trifluoracetic acid (TFA) for GAWK (1-17) and 30\% (vol/vol) ACN M $0.1 \%$ aqueous TFA for GAWK (20-38). The specific activity of GAWK (1-17) and GAWK (20-38) labels, as estimated by the self-displacement method (22), was 38 and 56 Becquerel/fmol, respectively. Standards were prepared gravimetrically from the synthetic GAWK fragments, lyophilized, and stored in vacuo at $-20^{\circ} \mathrm{C}$. Tissue extracts were assayed in duplicate using $0.1,1$, or $10 \mu$ l. The assay was performed in a total vol of $0.8 \mathrm{ml}$ of phosphate buffer $(0.06 \mathrm{M}, \mathrm{pH} 7.4$; $0.01 \mathrm{M}$ EDTA and $0.3 \%$ of BSA). For assay of plasma $1-, 10-$, or $100-\mu \mathrm{l}$ samples were used in duplicate. After $4 \mathrm{~d}$ incubation at $4^{\circ} \mathrm{C}$, free ${ }^{125} \mathrm{I}-\mathrm{GAWK}$ was separated from antibody-bound ${ }^{125} \mathrm{I}$-GAWK by adsorption of the latter to dextran-coated charcoal (6 mg/tube). These assays were capable of detecting changes (i.e., hormone additions) between assay tubes of 0.5 (GAWK [1-17]-LI) and $0.2 \mathrm{fmol}$ (GAWK [20-38]-LI) with $95 \%$ confidence. The dilution curves of plasma samples and tumor extracts, including VIPomas and pheochromocytomas, showed parallelism to both assay standards. The intra-assay variation of the GAWK (1-17) assay ranged from $12.3 \%$ at $12.4 \mathrm{pmol} /$ liter (1.24 fmol/tube) to $6.8 \%$ at $134 \mathrm{pmol} /$ liter $(13.4 \mathrm{fmol} /$ tube, $n=7)$, with corresponding interassay variations of 22 and $11 \%(n=10)$, respectively. The intra-assay variation of the GAWK (20-38) assay ranged from $11.3 \%$ at $9.8 \mathrm{pmol} /$ liter $(0.98 \mathrm{fmol} /$ tube $)$ to $5.2 \%$ at $205 \mathrm{pmol} /$ liter $(20.5 \mathrm{fmol} /$ tube, $n=7)$ with corresponding interassay variations of 18 and $7.8 \%(n=10)$, respectively.

Immunocytochemistry. Wax sections $(5 \mu \mathrm{m})$ of Bouin's solutionfixed endocrine tumors (see Table II) and normal adrenal gland were cut and allowed to dry on poly-L-lysine-coated slides (23) overnight at $37^{\circ} \mathrm{C}$. Dewaxed sections were immunostained by the peroxidase antiperoxidase technique (24) using antisera YE-4 and YS-1 at a dilution of 1:400. Control immunostaining included replacement of primary antisera with nonimmune serum, absorption of the antisera with homologous antigen, or absorption of YS-1 with GAWK (1-17) and of YE-4 with GAWK (20-38). A range of concentrations of antigens was used (0.1-10 $\mathrm{nmol} / \mathrm{ml}$ diluted antiserum).

Gel chromatographic procedures. Gel permeation chromatography of selected tumor extracts and plasma samples was performed on a 1.5 $\times 100-\mathrm{cm}$ column of Sephadex G-50 superfine (Pharmacia, Uppsala, Sweden). The column was eluted at $4^{\circ} \mathrm{C}$ with phosphate buffer $(0.06$ $\mathrm{M}, \mathrm{pH} 7.4 ; 0.01 \mathrm{M}$ EDTA; $0.3 \% \mathrm{BSA}$; and $0.2 \mathrm{M} \mathrm{NaCl}$ ) at a flow rate of $3.2 \mathrm{ml} / \mathrm{h}$, and $0.8 \mathrm{ml}$ was collected per fraction tube. The column was calibrated with dextran blue $(2,000,000 \mathrm{~mol} \mathrm{wt})$, horse heart cytochrome $c(12,384 \mathrm{~mol} \mathrm{wt})$, and a trace amount of ${ }^{125} \mathrm{I}-\mathrm{Na}$ as a bed volume marker. The eluted fractions and applied samples were assayed by both GAWK (1-17) and GAWK (20-38) RIAs. The recovery of all column runs was $76-125 \%$.

Fast protein liquid chromatography (FPLC). Selected tumor extracts, which had been prepared by passing through Minisart NML filter $(0.2 \mu \mathrm{m}, \mathrm{SM} 16534$; Sartorius, Gottingen, FRG), were subjected to reverse phase FPLC on a PepRPC column (C-18; Pharmacia). A gradient from 5-35\% solvent $B$ (solvent $A$, water in $0.1 \%$ TFA; solvent $\mathrm{B}, \mathrm{ACN}$ in $0.1 \% \mathrm{TFA}$ ) over $60 \mathrm{~min}$ was followed by another gradient from 35-50\% solvent B over $10 \mathrm{~min}$. The flow rate was $1 \mathrm{ml} / \mathrm{min}$, and 1-ml fractions were collected for subsequent assay of both GAWK (1-17)-LI and GAWK (20-38)-LI. The recovery of all column runs was $95-110 \%$.

Calculations. Concentrations of GAWK-LI are expressed in molar equivalents of synthetic GAWK fragments as picomoles per gram wet weight tissue or picomoles per liter plasma, and are given as the mean \pm SEM. The elution coefficient (Kav) for each immunoreactive peak was calculated according to the method of Laurent and Killander (25). Paired $t$ test was applied to compare the adrenal vein plasma concentrations with the corresponding simultaneously collected peripheral vein concentrations.

\section{Results}

GAWK-LI concentration in tissues. The concentration of GAWK-LI in normal human adrenal gland was GAWK 
(1-17)-LI, 1,328 $\pm 336 \mathrm{pmol} / \mathrm{g}$, and GAWK (20-38)-LI, $1,084 \pm 209 \mathrm{pmol} / \mathrm{g}(n=15)$. In normal pancreas it was $17.1 \pm 6.4$ and $26.5 \pm 14.1 \mathrm{pmol} / \mathrm{g}$, respectively $(n=8)$. The GAWK-LI content of various tumors is shown in Table I. Extremely high concentrations (GAWK [1-17]-LI, 18,173 $\pm 3,915$; GAWK [20-38]-LI, 17,852 $\pm 2,763 \mathrm{pmol} / \mathrm{g}$ ), which were at least 10 times higher than any other GAWKLI-producing tumors, were found in pheochromocytoma tissues. High concentrations of GAWK-LI were also found in carcinoid tumors, medullary carcinoma of thyroid, pancreatic endocrine tumors, ACTH-producing lung tumors, and a glomus tumor. On the other hand, low concentrations of GAWK-LI were found in nonendocrine tumors (e.g., squamous cell carcinomas and adenocarcinomas).

Immunocytochemistry. The results obtained for endocrine tumors using immunocytochemistry are displayed in Table II. Immunostaining of GAWK (20-38) (antiserum YS-1) gave more positive results than that of GAWK (1-17) (antiserum YE-4). Consistent positive staining was seen with both antisera in all pheochromocytomas studied (six of six; Fig. 2) and for YS-1 (GAWK 20-38) in all mid-gut carcinoid tumors (six of six; Fig. 3). The other types of endocrine tumors showed variable degrees of GAWK-EI, except for the nine cases of pulmonary small cell carcinoma which were all negative for both antisera. In addition, GAWK (20-38), but not GAWK (1-17), could be immunostained in cells of normal adrenal medulla (Fig. 4). Antisera specificity test showed that immunostaining

Table I. GAWK-LI Concentrations in Tumor Tissues

\begin{tabular}{lrcc}
\hline \multicolumn{1}{c}{ Tumor name } & No. & GAWK (1-17)-LI & GAWK (20-38)-LI \\
\hline Pheochromocytoma & 20 & $18,173 \pm 3,915$ & $17,852 \pm 2,763$ \\
GNB & 12 & $166 \pm 74$ & $212 \pm 74$ \\
Carcinoid tumor & 26 & $338 \pm 171$ & $635 \pm 379$ \\
MCT & 8 & $244 \pm 141$ & $703 \pm 430$ \\
Insulinoma & 18 & $357 \pm 288$ & $394 \pm 264$ \\
Glucagonoma & 8 & $295 \pm 212$ & $326 \pm 188$ \\
Gastrinoma & 15 & $492 \pm 369$ & $788 \pm 415$ \\
VIPoma & 19 & $369 \pm 267$ & $496 \pm 355$ \\
PPoma & 1 & 800 & 1,129 \\
SRIFoma & 2 & 2,100 & 4,149 \\
Adenoca (pancreas) & 11 & $72 \pm 43$ & $96 \pm 64$ \\
Nesidioblast (panc) & 5 & $51 \pm 8$ & $54 \pm 12$ \\
Parathyroid Tumor & 2 & 4 & 1 \\
Oat cell ca (lung) & 14 & $7 \pm 3$ & $15 \pm 6$ \\
Squam cell ca (lung) & 4 & $0.5 \pm 0.5$ & $1.5 \pm 1.5$ \\
Adenoca (lung) & 16 & $38.4 \pm 38$ & $36.3 \pm 36$ \\
ACTHoma (lung) & 3 & $376 \pm 122$ & $1,139 \pm 319$ \\
Adenoca (colon) & 3 & $7 \pm 6$ & $7 \pm 5$ \\
Hepatoma & 5 & $\mathrm{ND}$ & $\mathrm{ND}$ \\
Hypernephroma & 1 & 0.7 & 1.0 \\
Glomus tumor & 1 & 4,055 & 7,285 \\
Normal adrenal gland & 15 & $1,328 \pm 336$ & $1,084 \pm 209$ \\
Normal pancreas & 8 & $17.1 \pm 6.4$ & $26.5 \pm 14.1$ \\
& & & \\
\hline
\end{tabular}

GNB, MCT, ca, nesidioblast, panc, and ACTHoma (lung) are ganglioneuroblastoma, medullary carcinoma of thyroid, carcinoma, nesidioblastosis, pancreas, and ACTH-producing oat cell lung carcinoma, respectively. ND, not detected $(<0.2 \mathrm{pmol} / \mathrm{g})$.
Table II. Results of Immunostaining of GAWK-LI in Endocrine Tumors

\begin{tabular}{llrrr}
\hline & & & \multicolumn{2}{c}{ Positive } \\
\cline { 4 - 5 } \multicolumn{1}{c}{ Tumor site } & \multicolumn{1}{c}{ Tumor type } & No. & $\begin{array}{c}\text { GAWK } \\
(1-17)\end{array}$ & $\begin{array}{c}\text { GAWK } \\
(20-38)\end{array}$ \\
\hline Adrenal & Pheochromocytoma & 6 & 6 & 6 \\
Extra-adrenal & Paraganglioma & 6 & 4 & 4 \\
Mid-gut & Carcinoid & 6 & 0 & 6 \\
Rectum & Carcinoid & 4 & 1 & 2 \\
Lung & Carcinoid & 10 & 2 & 4 \\
Lung & Small cell carcinoma & 9 & 0 & 0 \\
Pancreas & VIPoma & 10 & 4 & 7 \\
Pancreas & Glucagonoma & 8 & 3 & 4 \\
Pancreas & Gastrinoma & 9 & 4 & 5 \\
Pancreas & Insulinoma & 9 & 1 & 3 \\
Pancreas & SRIF & 2 & 0 & 1 \\
& & & & \\
\hline
\end{tabular}

with YS- 1 and YE-4 could only be quenched by absorption with their homologous antigens.

Plasma concentration of GAWK-LI. Plasma from seven patients with different endocrine tumors showed a decrease of $31.2 \%$ for GAWK (1-17)-LI and 3.7\% for GAWK (20-38)-LI when left at room temperature for $24 \mathrm{~h}$, and a 35.8 and $15 \%$ decrease after $144 \mathrm{~h}$, respectively, showing that GAWK-LI, and particularly GAWK (20-38)-LI, is stable in plasma. GAWK-LI concentrations in normal human plasma were $7.0 \pm 1.1 \mathrm{pmol} / \mathrm{liter}$ (range, $0-15 \mathrm{pmol} / \mathrm{liter}$ ) for GAWK (1-17)-LI and 74 $\pm 5.0 \mathrm{pmol} /$ liter (range, $25-137 \mathrm{pmol} / \mathrm{liter}$ ) for GAWK $(20-38)$-LI $(n=40)$. To distinguish elevated plasma GAWK-LI concentrations, an arbitrary limit of 20 pmol/liter for GAWK (1-17)-LI and $150 \mathrm{pmol} / \mathrm{liter}$ for GAWK (20-38)-LI were chosen based on the highest normal value plus 2 SEM above the mean value. Plasma concentrations of GAWK-LI and the frequency of elevated GAWK-LI concentrations in plasma samples from patients with various tumors are depicted in Table III and Fig. 5.

Elevated plasma GAWK-LI was found in patients with pancreatic endocrine tumors (except gastrinomas), carcinoid tumors, and islet cell carcinomas. On the other hand, plasma concentrations of GAWK-LI were mostly normal in patients with pituitary tumors (ACTH-, GH-, and PRL-producing tumors), adrenal cortex tumors including one aldosteroneproducing tumor, nonendocrine tumors including adeno or squamous cell carcinomas, and medullary carcinoma of thyroid, and also in patients with duodenal ulcer and gastric ulcer. Neither were plasma levels of GAWK-LI greatly elevated in patients with pheochromocytomas and multiple endocrine adenomatosis (types 1 and 2; MEA). Patients suspected of having a VIPoma $(n=36)$, with high plasma VIP-like immunoreactivity levels ( $>30 \mathrm{pmol} /$ liter plasma) but no pancreatic tumor on radiological levels of GAWK-LI, were in the normal ranges without exception. After successful tumor excision in patients with demonstrable VIPoma $(n=4)$ and pheochromocytoma $(n=1)$, plasma levels of GAWK-LI decreased to normal values (Fig. 6). Plasma concentrations of GAWK (20-38)-LI in the adrenal vein $(266 \pm 51 \mathrm{pmol} / \mathrm{liter}$, mean \pm SEM) was approximately four times higher than that in peripheral samples $(67 \pm 10 \mathrm{pmol} / \mathrm{liter}, P<0.005, n=12$; Fig. 7). 


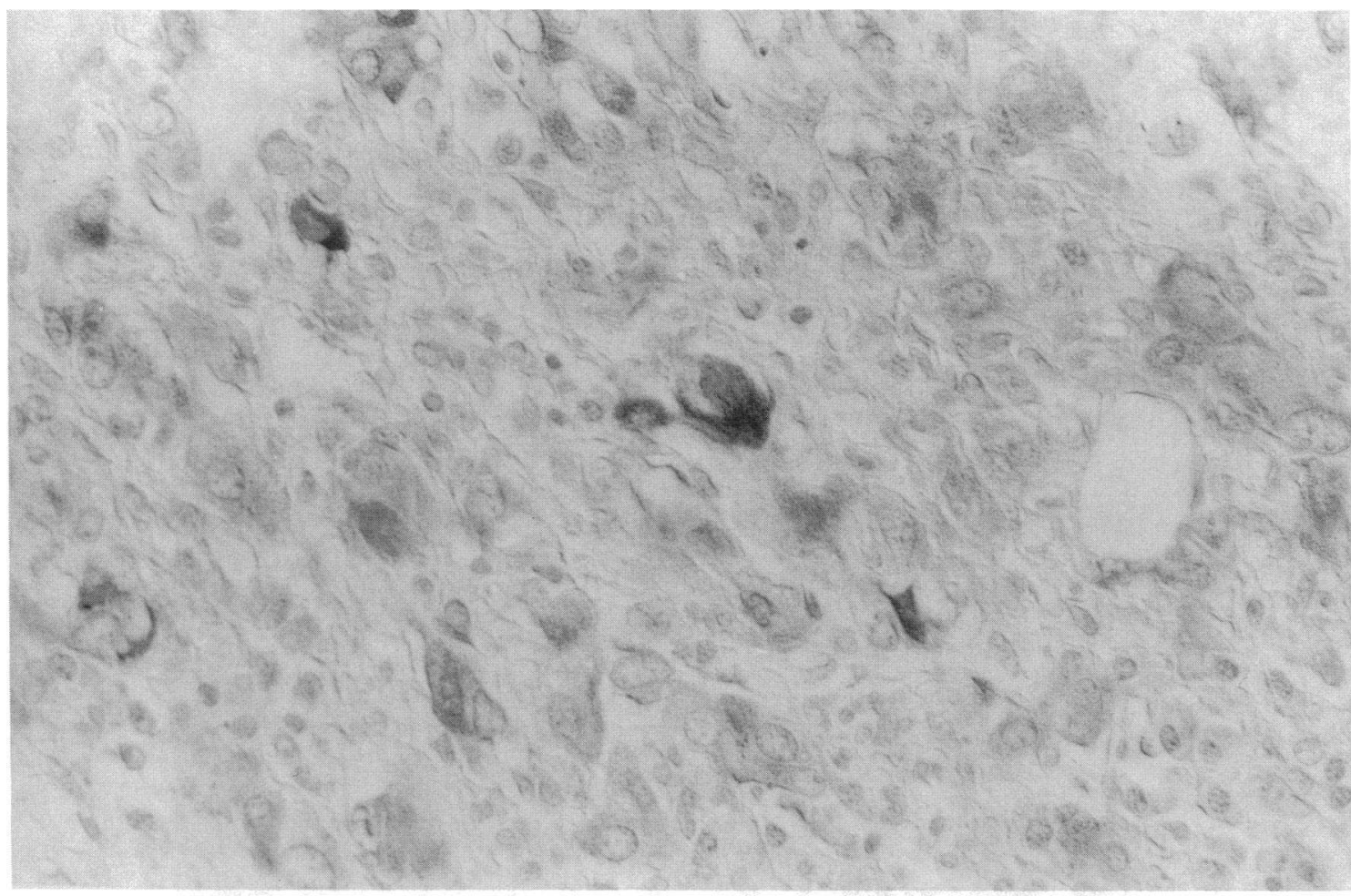

Figure 2. Scattered cells in a pheochromocytoma showing immunoreactivity for GAWK (20-38). Nomarski optics. $\times 350$.

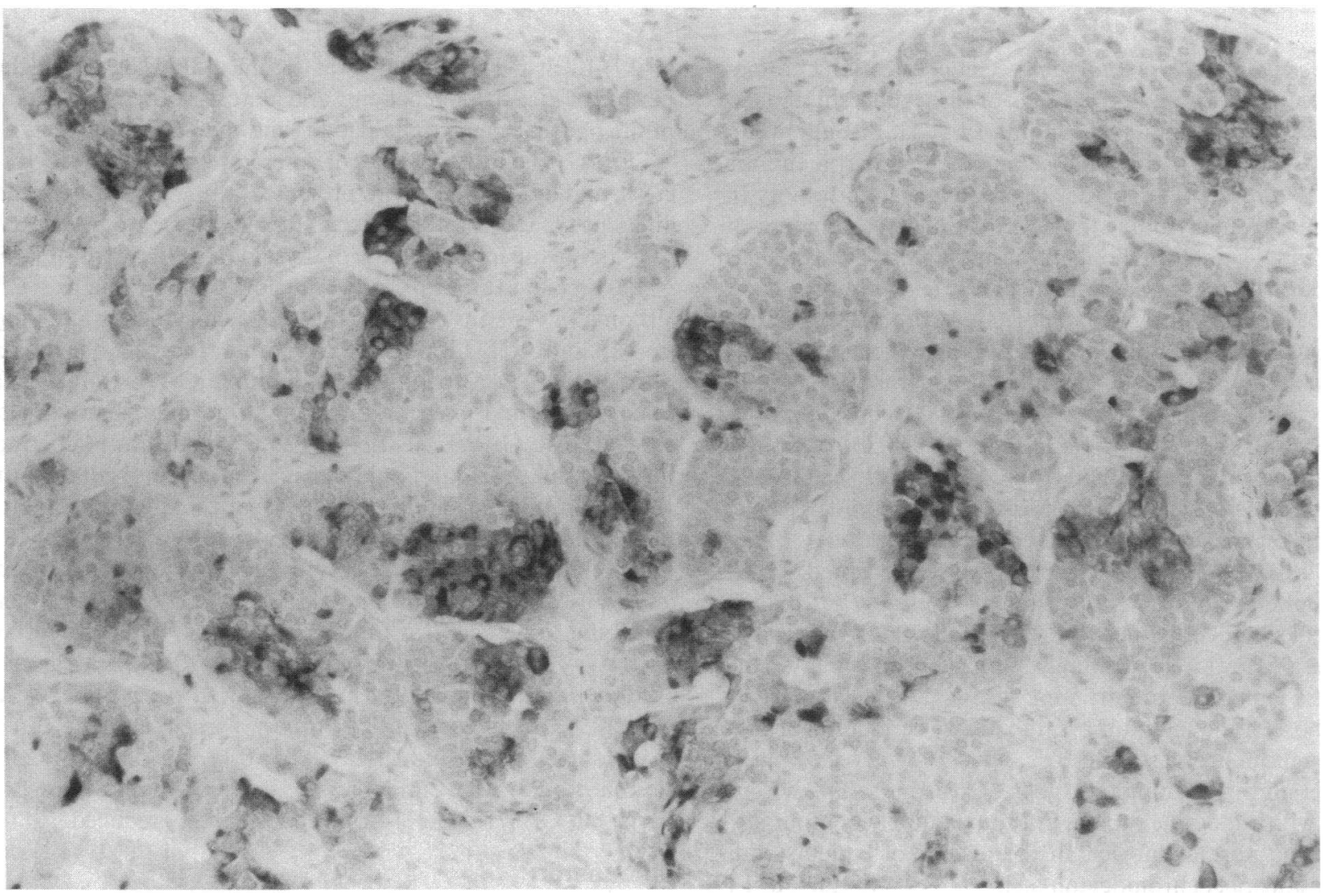

Figure 3. A low-power micrograph showing GAWK (20-38) immunostained in a proportion of cells of a mid-gut (ileal) argentaffin carcinoid tumor. $\times 150$. 


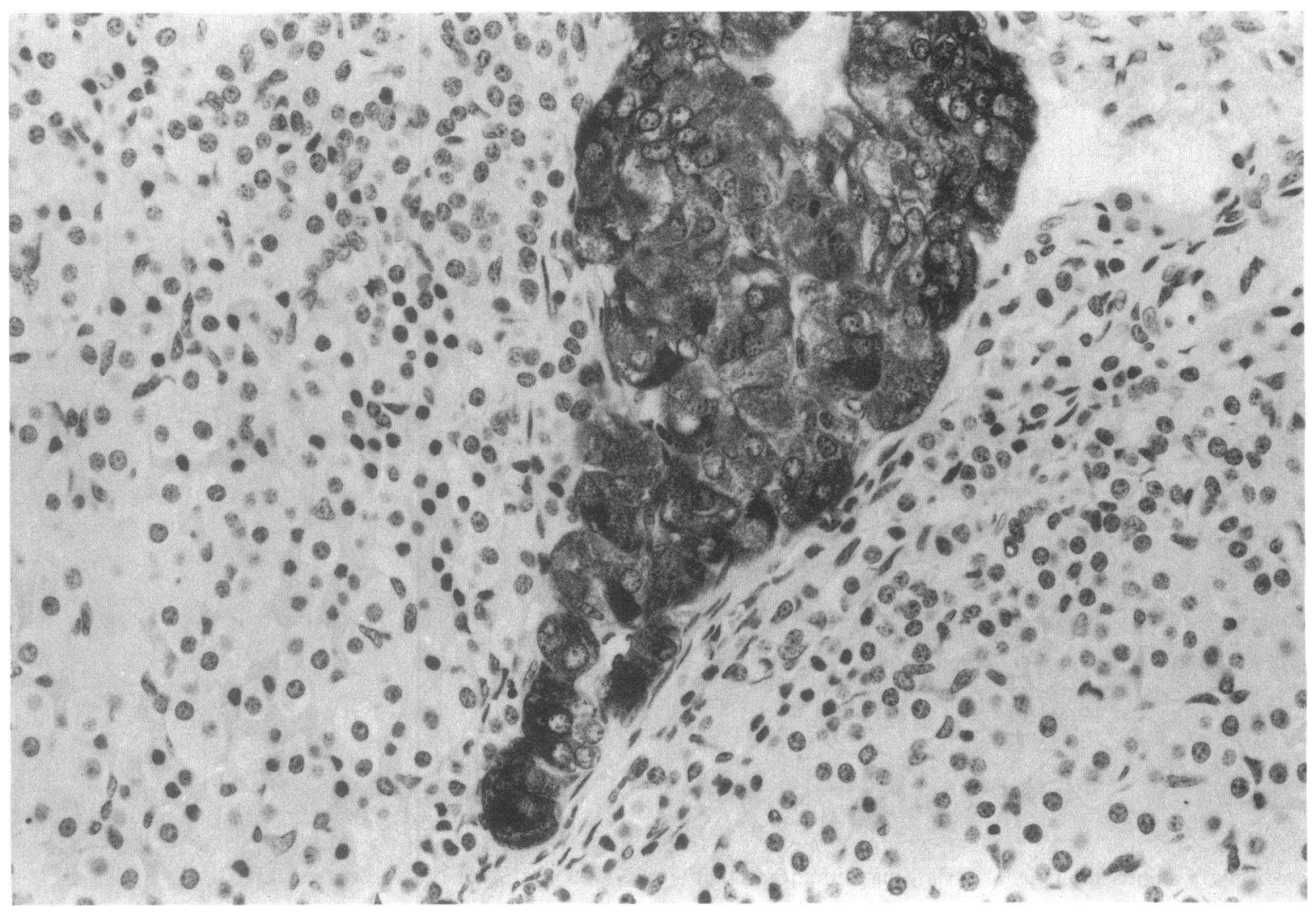

Figure 4. GAWK (20-38) immunoreactivity immunostained in cells of the normal adrenal medulla. The surrounding cells are adrenal gland cortical cells. $\times 250$.

Gel permeation chromatography. Gel permeation chromatography was performed on extracts of three different pancreatic endocrine tumors (glucagonoma $[n=1]$, insulinoma [ $n$ $=3]$, and VIPoma $[n=1])$ and some other endocrine tumors (carcinoid tumor $[n=3]$, ACTH-producing lung tumors $[n$ $=2]$, pheochromocytomas $[n=7]$, medullary carcinoma of thyroid [ $n=1]$, and ganglioneuroblastoma $[n=1])$, as well as on normal pancreas and adrenal gland (Fig. 8). In almost all profiles of these samples, two major GAWK (20-38)-LI peaks were recognized. The predominant peak emerged at a Kav of $0.38 \pm 0.006$ (range, $0.36-0.41$ ), with a lesser amount in a peak at a Kav of $0.27 \pm 0.005$ (range, $0.26-0.28$ ). Three minority peaks (Kav 0.02-0.04, 0.55-0.60, and 0.66-0.70) were also seen. On the other hand, only one major peak of GAWK (1-17)-LI was recognized, at a Kav of $0.61 \pm 0.007$ (range, 0.59-0.63). Three peaks of very small quantity (Kav $0.03-0.04,0.09-0.1$, and $0.26-0.27$ ) were also noted. However, in pheochromocytomas and normal adrenal glands major peaks were found near the void volume, and the profiles from these tissues were strikingly similar. The profiles of the pancreatic endocrine tumors were also similar to each other and to those of the lung tumors, medullary carcinoma of thyroid, ganglioneuroblastoma, and normal pancreas. Fig. 9 shows gel chromatographic profiles of plasma samples from patients with endocrine tumors (VIPoma and pheochromocytoma) and a normal subject. In the plasma of patients with VIPoma and pheochromocytoma, three GAWK (20-38)-LI peaks were found in the same positions as those of matched tumor extracts. On the other hand, the peak of GAWK
(1-17)-LI at a Kav of 0.61 was significantly reduced in the plasma of the VIPoma patients and almost disappeared in that of the pheochromocytoma patient and the normal subject.

FPLC. The FPLC profiles of different tumors, normal pancreas, and adrenal gland are presented in Fig. 10. In the nine different types of tumor extracts studied (pheochromocytoma $[n=5]$, medullary carcinoma of thyroid [ $n=2]$, gastrinoma [ $n$ $=2]$, carcinoid tumor $[n=4]$, ganglioneuroblastoma $[n=2]$, VIPoma [ $n=3]$, insulinoma [ $n=4]$, adenocarcinoma of lung $[n=1]$, and ACTH-producing lung tumor $[n=2])$, one major peak of GAWK (20-38)-LI and multiple GAWK (1-17)-LI peaks were found in each tumor and in normal pancreas and adrenal. The GAWK (1-17)-LI FPLC profiles of endocrine tumors and normal pancreas looked very similar, but pheochromocytoma and normal adrenal gland were different. In pheochromocytoma, the major peak of GAWK (20-38)-LI, which eluted at 34-35 min, corresponded to two peaks when rerun on the gel column (Kav 0.03 and 0.38 ). On the other hand, the three peaks of GAWK (1-17)-LI, which eluted at 9-10, 14-15, and 18-19 min, corresponded to one peak on the G-50 gel column (Kav 0.61). The fourth peak of GAWK (1-17)-LI, which eluted at 35-36 min, corresponded to three peaks on the gel column (Kav 0.03, 0.1, and 0.26). Patient plasma profiles were similar to the corresponding tumor extracts, but GAWK (1-17)-LI was considerably reduced.

\section{Discussion}

In this study, immunoreactivity indicative of GAWK (chromogranin-B 420-493) was found in high concentrations in a 
Table III. GAWK-LI Concentrations in the Plasma Samples

\begin{tabular}{|c|c|c|c|c|c|c|}
\hline \multirow[b]{2}{*}{ Disease or tumor name } & \multicolumn{3}{|c|}{ GAWK (1-17)-LI } & \multicolumn{3}{|c|}{ GAWK (20-38)-LI } \\
\hline & No. & $\mathrm{M} \pm \mathrm{SEM}$ & $\%$ & No. & $\mathbf{M} \pm \mathrm{SEM}$ & $\%$ \\
\hline Pheochromocytoma & 9 & $121 \pm 66$ & 56 & 12 & $114 \pm 19$ & 33 \\
\hline GNB & & $*$ & & 1 & 97 & 0 \\
\hline Carcinoid & & * & & 7 & $744 \pm 218$ & 86 \\
\hline MCT & 3 & $7.3 \pm 1.7$ & 0 & 4 & $100 \pm 5$ & 0 \\
\hline Insulinoma & 3 & $406 \pm 170$ & 100 & 3 & $596 \pm 181$ & 100 \\
\hline Glucagonoma & 23 & $144 \pm 11$ & 100 & 34 & $482 \pm 98$ & 85 \\
\hline Gastrinoma & 32 & $13 \pm 5$ & 16 & 35 & $95 \pm 12$ & 14 \\
\hline VIPoma & 25 & $442 \pm 99$ & 80 & 30 & $981 \pm 199$ & 83 \\
\hline SRIFoma & 15 & $152 \pm 96$ & 53 & 17 & $180 \pm 54$ & 24 \\
\hline PPoma & 2 & 628 & 50 & 3 & $535 \pm 266$ & 67 \\
\hline GRHoma (pancreas) & 1 & 48 & 100 & 1 & 187 & 100 \\
\hline Adenoca (pancreas) & 7 & $30 \pm 8$ & 43 & 8 & $262 \pm 109$ & 50 \\
\hline Nesidioblast (panc) & & * & & 1 & 145 & 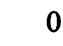 \\
\hline Hepatoma & 63 & $9 \pm 3$ & 6 & 63 & $82 \pm 9$ & \\
\hline Cushing's & 9 & $5.6 \pm 1.4$ & 0 & 24 & $54 \pm 6$ & 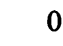 \\
\hline Adrenal adenoma & 4 & $5 \pm 3$ & 0 & 5 & $55 \pm 9$ & ( \\
\hline PRLoma & 2 & 6.5 & 0 & 6 & $82 \pm 12$ & 0 \\
\hline Acromegaly (GHoma) & & * & & 20 & $50 \pm 5$ & \\
\hline Addison's & & * & & 4 & $51 \pm 7$ & \\
\hline MEA (Type $1 \& 2$ ) & 24 & $118 \pm 82$ & 50 & 41 & $130 \pm 16$ & 22 \\
\hline Adenoca (lung) & 1 & 12.5 & 0 & 1 & 75 & \\
\hline Adenoca (colon) & 8 & $5 \pm 1$ & 0 & 8 & $51 \pm 7$ & \\
\hline Lymphoma & 1 & $5>$ & 0 & 1 & 50 & \\
\hline Menetrier's & 1 & 7.1 & 0 & 1 & 88 & \\
\hline Hyperparathyroidism & 3 & $7 \pm 6$ & 0 & 3 & $83 \pm 14$ & \\
\hline VIPoma suspicious & 36 & $11 \pm 5.3$ & 3 & 36 & $74 \pm 25$ & \\
\hline Hyper PPemia & 5 & $11 \pm 1.6$ & 0 & 5 & $87 \pm 13$ & \\
\hline Ulcer (duod, gast) & & * & & 60 & $73 \pm 4$ & \\
\hline Normal & 40 & $7.0 \pm 1.1$ & 0 & 40 & $74 \pm 5$ & \\
\hline
\end{tabular}

All the mean \pm SEM data are presented by picomoles per liter plasma. $\%$, the incidence of raised values ( $20 \mathrm{pmol} / \mathrm{liter}$ for GAWK [1-17]-LI and $150 \mathrm{pmol} /$ liter for GAWK [20-38]-LI).

* No data. GNB, MCT, CA, Nesidioblast, Panc, MEA, Duod, and Gast are ganglioneuroblastoma, medullary carcinoma of thyroid, carcinoma, nesidioblastosis, pancreas, multiple endocrine adenomatosis, duodenal, and gastric, respectively.

wide range of endocrine tumor extracts as well as in plasma from such tumor patients. These RIA and immunohistochemistry data correlate with the previous histochemical and immunoblotting data for $\mathrm{CgA}$ and $\mathrm{CgB}$ which have been reported to be produced by endocrine tumors $(5,9,16,19$, 26-30) and which suggested that the two different chromogranins (A and B) coexisted in endocrine tumors. Although the concentration of GAWK-LI in extracts of pheochromocytomas was $\sim 10$ times higher than that found in extracts of whole adrenal gland, the concentrations in the adrenal medulla could not be compared as it was not possible to dissect this tissue in its entirety for comparison. Similarly, pancreatic endocrine tumors average 20 times higher concentrations than whole pancreas although normal islets (the main endocrine tissue within the pancreas) may contain even higher concentrations. Plasma levels of $\mathrm{CgA}$ in patients with pheochromo-

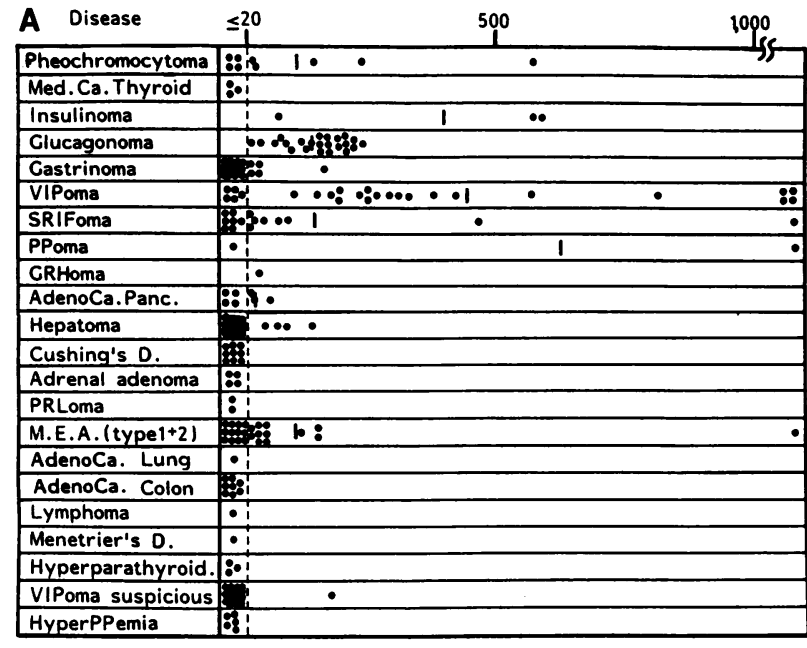

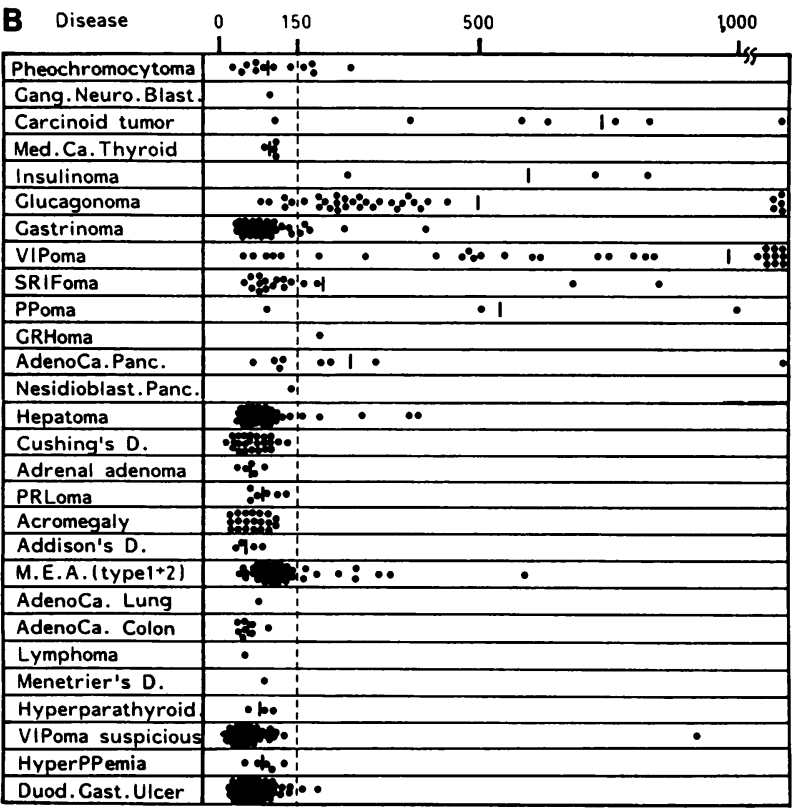

Figure 5. GAWK (chromogranin-B)-LI concentrations (picomoles per liter) in plasma $(A)$ GAWK (1-17)-LI and $(B)$ GAWK (20-38)-LI from patients with various tumors. The vertical dashed lines denote upper limit of normal values of GAWK (1-17)-LI and GAWK (20-38)-LI, 20 and $150 \mathrm{pmol} /$ liter, respectively. The mean for each group is shown by the vertical solid lines. Gang. Neuro. Blast., Med. Ca. Thyroid, Ca. Panc., Nesidioblast., MEA, Duod., and Gast. are ganglioneuroblastoma, medullary carcinoma of thyroid, carcinoma of pancreas, nesidioblastosis, endocrine adenomatosis, duodenal, and gastric, respectively. The GRFoma originated from the pancreas.

cytomas are much lower than the concentrations seen in carcinoid tumor or pancreatic islet cell tumor patients (16-19), a result similar to our present findings for GAWK-LI. Plasma GAWK-LI in the endocrine tumor patients is probably mostly tumor derived as the concentrations of GAWK-LI decrease to normal after successful removal of tumor. Plasma GAWK-LI in normal subjects may originate, at least in part, from the adrenal gland, as plasma concentrations of GAWK-LI in the adrenal vein are significantly higher than in peripheral plasma. 

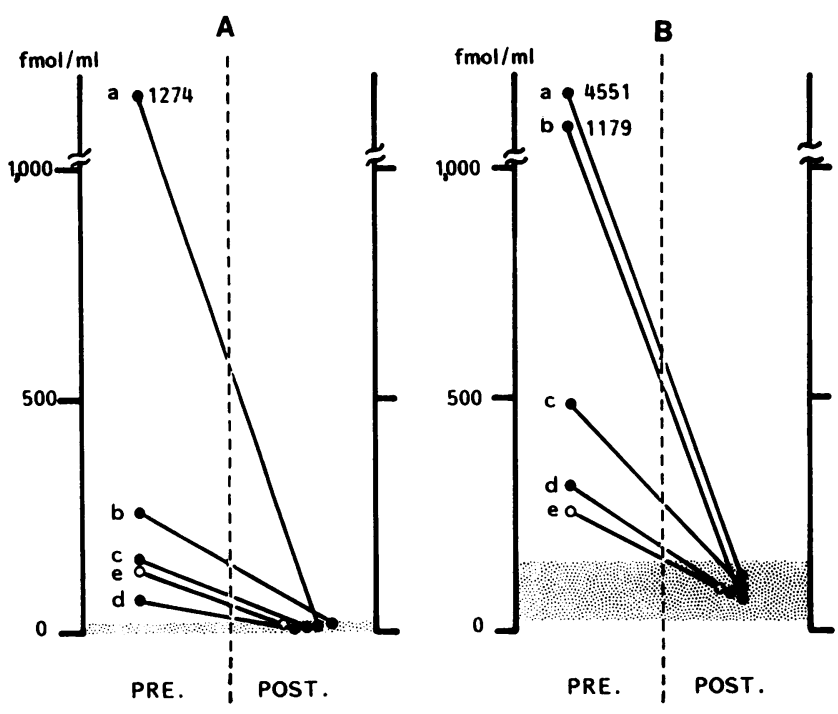

Figure 6. The change of GAWK (chromogranin-B)-LI concentrations in the plasma from patients with VIPomas $(a-d)$ and pheochromocytoma $(e)$ before and after tumor removal. $(A)$ GAWK (1-17)-LI; (B) GAWK (20-38)-LI. Shades indicate normal ranges.

Normal levels of plasma GAWK-LI in patients with pituitary endocrine tumors suggest that GAWK may not be released in significant amounts, differing from other pituitary adenoma hormones such as ACTH, GH, or PRL. Interestingly, the concentrations of GAWK-LI stored in tumors did not correlate with the plasma GAWK-LI concentrations associated with these tumors, for example in the patients with pheochromocytoma, gastrinoma, and medullary carcinoma of thyroid. Thus, pheochromocytomas had the highest mean tumor concentration, but only about half the pheochromocytoma patients had

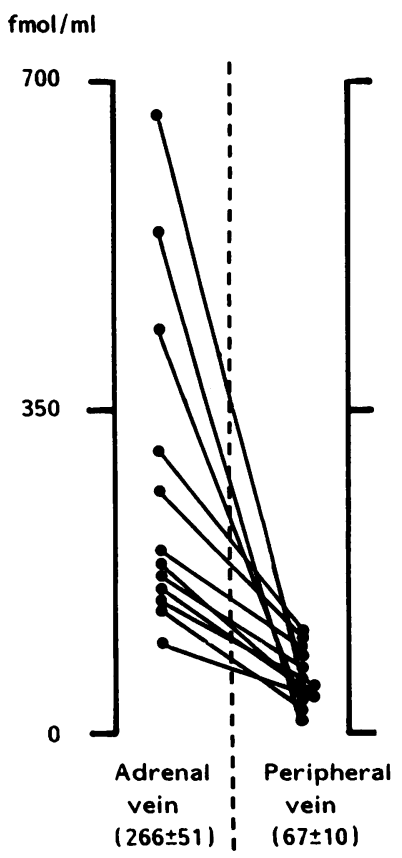

Figure 7. GAWK (20-38)-LI concentrations in plasma from the adrenal vein and the peripheral vein collected from patients during adrenal venography $(n=12)$.
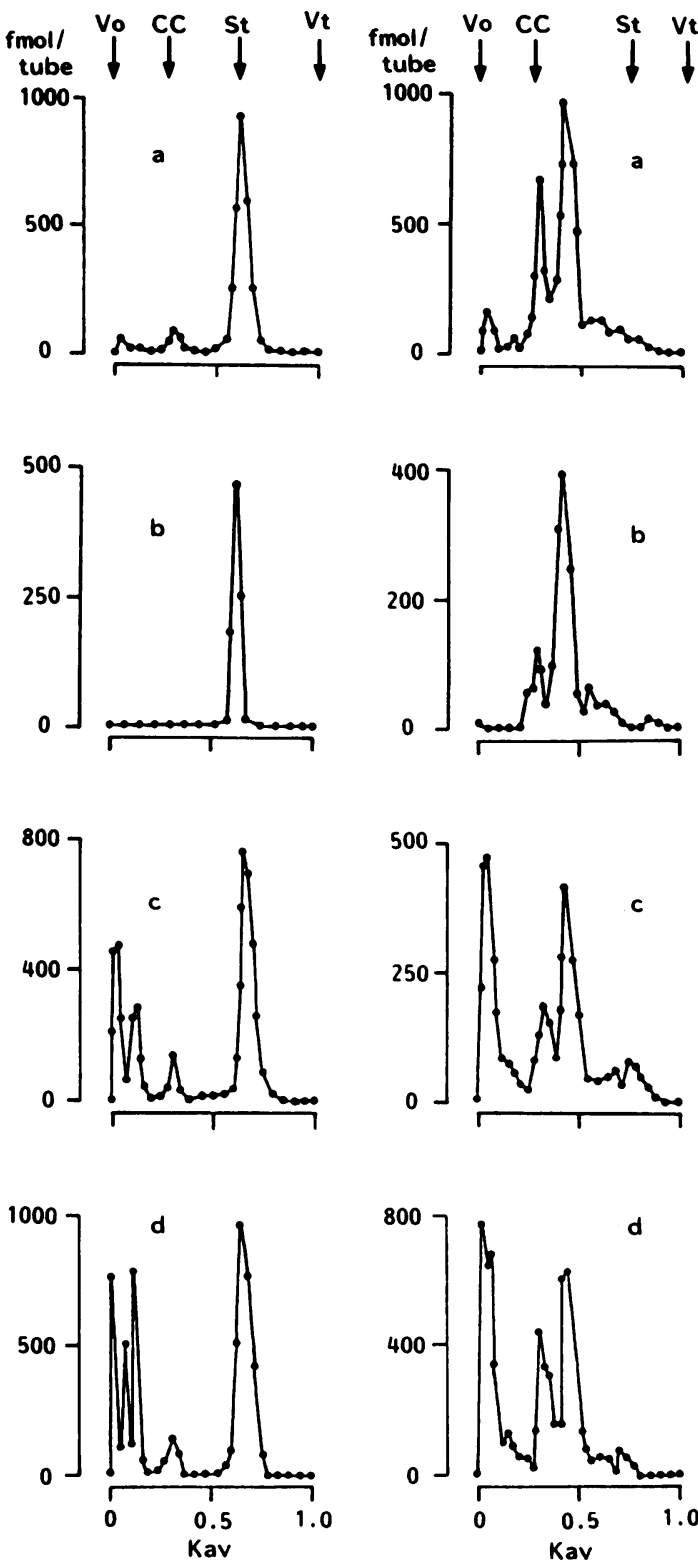

Figure 8. Sephadex G-50 gel permeation profiles of GAWK (1-17)LI (left) and GAWK (20-38)-LI (right) in extracts of VIPoma (a), normal pancreas $(b)$, pheochromocytoma $(c)$, and normal adrenal gland $(d)$. The column was calibrated with dextran blue $(V o)$, horse heart cytochrome $c(C C)$, and ${ }^{125} \mathrm{I}-\mathrm{Na}(V t)$ as molecular size markers. $S t$ shows GAWK (1-17, 20-38) standards elution positions. The concentrations of GAWK-LI are expressed as femtomoles per fraction.

elevated plasma GAWK-LI levels, and these were only moderately raised. The same phenomenon was also observed in gastrinoma and medullary carcinoma of thyroid patients. It may be that pheochromocytoma, gastrinoma, and medullary carcinoma of thyroid synthesize GAWK $(\mathrm{CgB})$ but do not release it readily. Alternatively, it may be that in pheochromocytoma mainly high molecular weight forms of GAWK (possibly the whole $\mathrm{CgB}$ molecule) are produced, while other tumors produce mainly smaller molecular forms. The processing of the peptide in pheochromocytoma and the adrenal gland may thus be different from that in other tumors or peripheral tis- 
sues. In contrast, pancreatic endocrine tumors, especially VIPomas and glucagonomas, were characterized by relatively low tissue concentrations, compared with those of pheochromocytomas, and a high prevalence of elevated plasma GAWK-LI levels. This suggests that these tumors secrete the peptide rapidly but store relatively little. It might indeed be that $\mathrm{CgB}$ is completely processed to small molecular forms in pancreatic endocrine tumors (11). For many of the endocrine tumors studied here, diagnosis by means of plasma hormone estimations is not always clear-cut. The addition of a further potential tumor marker to the plasma assay screen may, therefore, prove helpful. Thus, while not all samples from patients with endocrine tumors would be positive, when the GAWK-LI concentrations were in the tumor range, this might provide supportive evidence that such a tumor existed. If a bank of similar markers, including 7B2 (31) and pancreatic polypeptide (32) were measured, this would increase the likelihood of tumor detection, and if several were positive, would add supportive evidence to the diagnosis. Similarly, with those tumors that were found to be producing high concentrations of particular markers, these could be of use in the detection of tumor
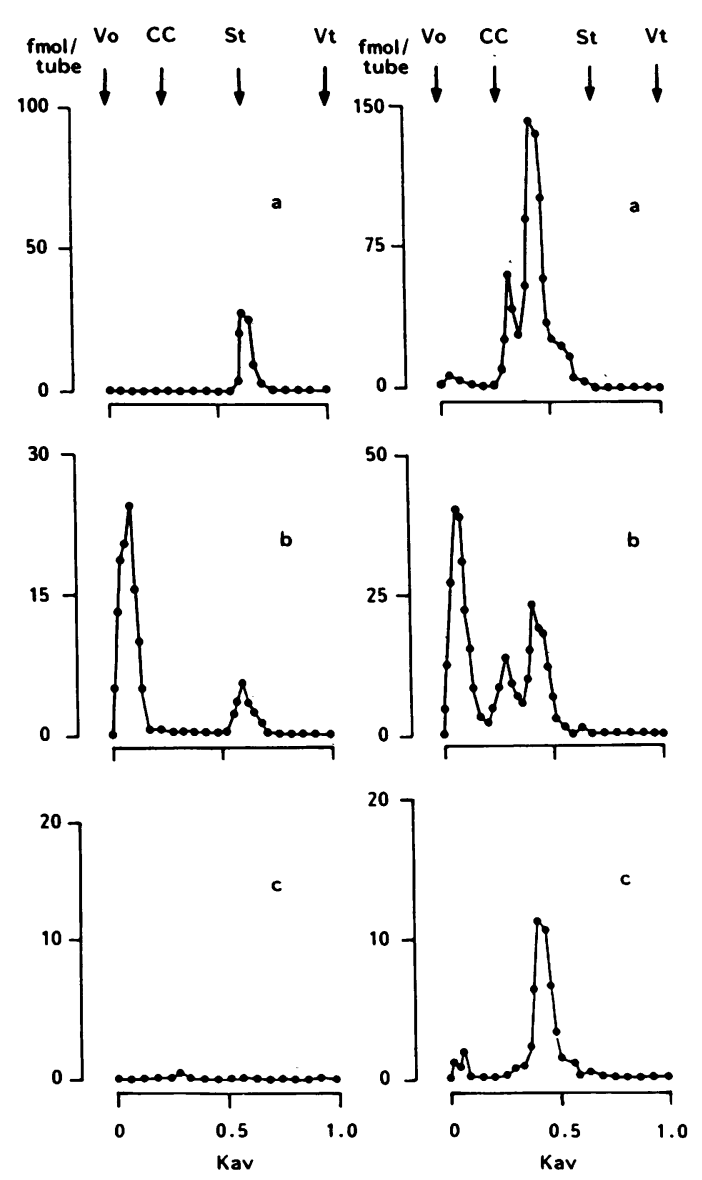

Figure 9. Sephadex G-50 gel permeation profiles of GAWK (1-17)LI (left) and GAWK (20-38)-LI (right) in plasma from the patients with VIPoma (a), pheochromocytoma $(b)$, and normal subject $(c)$. The column was calibrated with dextran blue $(V o)$, horse heart cytochrome $c(C C)$, and ${ }^{125} \mathrm{I}-\mathrm{Na}(V t)$ as molecular size markers. St shows GAWK $(1-17,20-38)$ standards elution positions. The concentrations of GAWK-LI are expressed as femtomoles per fraction.
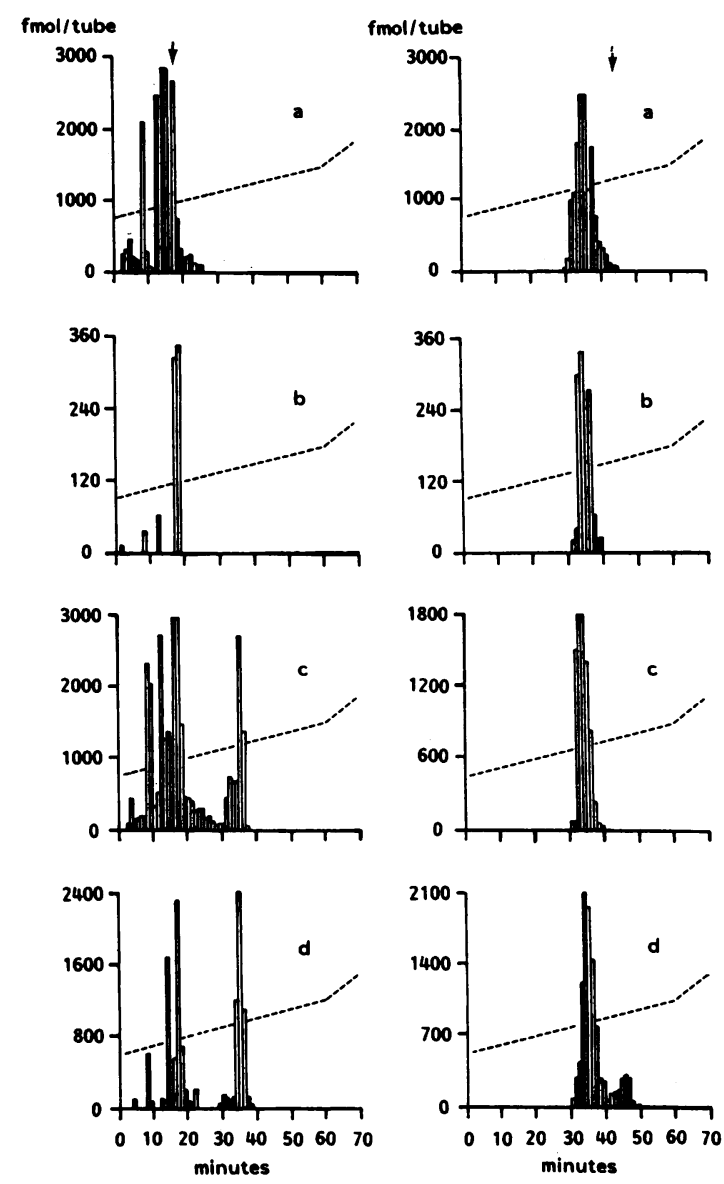

Figure 10. Fractionation of GAWK (1-17)-LI (left) and GAWK (20-38)-LI (right) from extracts of VIPoma (a), normal pancreas $(b)$, pheochromocytoma $(c)$, and normal adrenal gland $(d)$ by reverse phase FPLC. An ACN gradient (-- -) (see Methods) was used at a flow rate of $1 \mathrm{ml} / \mathrm{min}$. The concentrations of GAWK-LI are expressed as femtomoles per fraction.

recurrence after prospective studies in large numbers of patients, and it is now necessary to investigate these possibilities.

\section{Acknowledgments}

The authors are grateful to Mrs. Kay Davies for her critical reading and useful discussion.

\section{References}

1. Benjannet, S., R. Leduc, C. Lazure, N. G. Seidah, M. Marcinkiewicz, and M. Chretien. 1985. GAWK, a novel human pituitary polypeptide: isolation, immunocytochemical localisation and complete amino acid sequence. Biochem. Biophys. Res. Commun. 126:602-609.

2. Benjannet, S., R. Leduc, N. Adrouche, J. P. Falgueyret, M. Marcinkiewicz, N. G. Seidah, M. Mbikay, C. Lazure, and M. Chretien. 1987. Chromogranin B (secretogranin 1), a putative precursor of two novel pituitary peptides through processing at paired basic residues. FEBS (Fed. Eur. Biochem. Soc.) Lett. 224:142-148.

3. Benedum, U. M., A. Lamouroux, D. S. Konecki, P. Rosa, A. Hille, P. A. Baeuerle, R. Frank, F. Lottspeich, J. Mallet, and W. B. Huttner. 1987. The primary structure of human secretogranin 1 (chromogranin B): comparison with chromogranin A reveals homolo- 
gous terminal domains and a large intervening variable region. $E M B O$ (Eur. Mol. Biol. Organ.) J. 6:1203-1211.

4. Carmichael, S. W., and H. Winkler. 1985. The adrenal chromaffin cell. Sci. Am. 252:30-39.

5. Cohn, D. V., J. J. Elting, M. Frick, and R. Elde. 1984. Selective localisation of the parathyroid secretory protein-1 adrenal medulla chromogranin a protein family in a wide variety of endocrine cells of the rat. Endocrinology. 114:1963-1973.

6. O'Connor, D. T. 1983. Chromogranin: widespread immunoreactivity in polypeptide hormone producing tissues and serum. Regul. Pept. 6:263-280.

7. O'Connor, D. T., D. Burton, and L. J. Deftos. 1983. Chromogranin A: immunohistology reveals its universal occurrence in normal polypeptide hormone producing endocrine glands. Life Sci. 33:16571663.

8. Wilson, B. S., and R. V. Lloyd. 1984. Detection of chromogranin in neuroendocrine cells with a monoclonal antibody. Am. J. Pathol. 115:459-468.

9. Angeletti, R. H. 1986. Chromogranins and neuroendocrine secretion. Lab. Invest. 55:387-390.

10. O'Connor, D. T., and R. P. Frigon. 1984. Chromogranin A, the major catecholamine storage vesicle soluble protein: multiple size forms, subcellular storage, and regional distribution in chromaffin and nervous tissue elucidated by radioimmunoassay. J. Biol. Chem. 259:3237-3247.

11. Facer, P., A. E. Bishop, R. V. Lloyd, B. S. Wilson, R. J. Hennessy, and J. M. Polak. 1985. Chromogranin: a newly recognised marker for endocrine cells of the human gastrointestinal tract. Gastroenterology. 89:1366-1373.

12. Walts, A. E., J. W. Said, I. P. Shintaku, and R. V. Lloyd. 1985. Chromogranin as a marker of neuroendocrine cells in cytologic material: an immunocytochemical study. Am. J. Clin. Pathol. 84:273-277.

13. Rindi, G., R. Buffa, F. Sessa, O. Tortora, and E. Solcia. 1986. Chromogranin A, B and C immunoreactivities of mammalian endocrine cells: distribution, distinction from co-stored hormones/pro-hormones and relationship with the argyrophil component of secretory granules. Histochemistry. 85:19-28.

14. Konecki, D. S., U. M. Benedum, H. H. Gerdes, and W. B. Huttner. 1987. The primary structure of human chromogranin A and pancreastatin. J. Biol. Chem. 262:17026-17030.

15. Sekiya, K., M. A. Ghatei, N. Minamino, D. Bretherton-Watt, H. Matsuo, and S. R. Bloom. 1988. Isolation of human pancreastatin fragment containing the active sequence from a glucagonoma. FEBS (Fed. Eur. Biochem. Soc.) Lett. 228:153-156.

16. O'Connor, D. T., and L. J. Deftos. 1986. Secretion of chromogranin A by peptide-producing endocrine neoplasms. N. Engl. J. Med. 314:1145-1151.

17. O'Connor, D. T., and K. N. Bernstein. 1984. Radioimmunoassay of chromogranin $\mathrm{A}$ in plasma as a measure of exocytotic sympathoadrenal activity in normal subjects and patients with pheochromocytoma. N. Engl. J. Med. 311:764-770.

18. O’Connor, D. T., R. P. Frigon, and R. L. Sokoloff. 1984.
Human chromogranin A: purification and characterisation from catecholamine storage vesicles of human pheochromocytoma. Hypertension. 6:2-12.

19. O'Connor, D. T., D. G. Burton, and L. J. Deftos. 1983. Immunoreactive human chromogranin $\mathrm{A}$ in diverse polypeptide hormone producing human tumors and normal endocrine tissues. J. Endocrinol. Metab. 57:1084-1086.

20. Avrameas, S., and T. Ternynck. 1969. The cross-linking of proteins with glutaraldehyde and its use for the preparation of immunoadsorbents. Immunochemistry. 6:53-59.

21. Hunter, W. M., and F. C. Greenwood. 1962. Preparation of iodine-131 labelled human growth hormone of high specific activity. Nature (Lond.). 194:495-497.

22. Feldman, H., and D. Rodbard. 1971. Mathematical theory of radioimmunoassay. In Principles of Competitive Protein Binding Assays. W. D. Odell and W. H. Daughaday, editors, J. B. Lippincott Co., Philadelphia. 138 pp.

23. Huang, W. M., S. J. Gibson, P. Facer, J. Gu, and J. M. Polak. 1983. Improved adhesion for immunocytochemistry using high molecular weight polymers of L-lysine as a slide coating. Histochemistry. 77:275-279.

24. Sternberger, L. A., P. H. Hardy, J. J. Cuculis, and H. G. Meyer. 1970. The unlabelled antibody enzyme method of immunocytochemistry: preparation and properties of soluble antigen-antibody complex (horse radish peroxidase-antiperoxidase) and its use in the identification of spirochetes. J. Histochem. Cytochem. 18:315-333.

25. Laurent, T. C., and J. Killander. 1964. A theory of gel filtration and its experimental verification. J. Chromatogr. 14:317-330.

26. Fischer-Colbrie, R., and I. Frischenschlager. 1985. Immunological characterisation of secretory proteins of chromaffin granules: chromogranins A, chromogranins B and enkephalin-containing peptide. J. Neurochem. 44:1854-1861.

27. Fischer-Colbrie, R., H. Lassmann, C. Hagn, and H. Winkler. 1985. Immunological studies on the distribution of chromogranin A and $B$ in endocrine and nervous tissues. Neuroscience. 16:547-555.

28. Lloyd, R. V., M. Blaivas, and B. S. Wilson. 1985. Distribution of chromogranin and $\mathrm{S} 100$ protein in normal and abnormal adrenal medullary tissues. Arch. Pathol. Lab. Med. 109:633-635.

29. Lloyd, R. V., B. S. Wilson, K. Kovacs, and N. Ryan. 1985. Immunohistochemical localisation of chromogranin in human hypophyses and pituitary adenomas. Arch. Pathol. Lab. Med. 109:515-517.

30. Lloyd, R. V., M. Cano, P. Rosa, A. Hille, and W. B. Huttner. 1988. Distribution of chromogranin A and secretogranin I (chromogranin B) in neuroendocrine cells and tumors. Am. J. Pathol. 130:296-304.

31. Suzuki, H., M. A. Ghatei, S. J. Williams, L. O. Uttenthal, P. Facer, A. E. Bishop, J. M. Polak, and S. R. Bloom. 1986. Production of pituitary protein 7B2 immunoreactivity by endocrine tumors and its possible diagnostic value. J. Clin. Endocrinol. Metab. 63:758-765.

32. Wynick, D., S. J. Williams, and S. R. Bloom. 1988. Symptomatic secondary hormone syndromes in patients with established malignant pancreatic endocrine tumors. N. Engl. J. Med. 319:605-607. 